\title{
Gestational Protein Restriction in Mice Has Pronounced Effects on Gene Expression in Newborn Offspring's Liver and Skeletal Muscle; Protective Effect of Taurine
}

\author{
OLE HARTVIG MORTENSEN, HANNE LODBERG OLSEN, LIS FRANDSEN, PETER EIGIL NIELSEN, FINN CILIUS NIELSEN,
} NIELS GRUNNET, AND BJØRN QUISTORFF

\begin{abstract}
Department of Biomedical Sciences [O.H.M., L.F., N.G., B.Q.]; Department of Cellular and Molecular Medicine [H.L.O., P.E.N.], University of Copenhagen, 2200 Copenhagen, Denmark; Department of Clinical Biochemistry [F.C.N.], University of Copenhagen, 2100 Copenhagen, Denmark
\end{abstract}

\begin{abstract}
We examined gene expression changes in liver and skeletal muscle of newborn mice subjected to a maternal low protein (LP) or normal protein (NP) diet during pregnancy, with or without taurine supplementation in the drinking water. LP offspring had a $40 \%$ lower birthweight than NP offspring, whereas it was reduced by only $20 \%$ with taurine supplementation. Microarray gene expression analysis revealed significant changes in 2012 genes in liver and 967 genes in skeletal muscle of LP offspring. By unknown mechanisms, taurine partially or fully prevented 30 and $46 \%$ of these expression changes, respectively. Mitochondrial genes, in particular genes associated with oxidative phosphorylation, were more abundantly changed in LP offspring, with primarily up-regulation in liver but down-regulation in skeletal muscle. In both tissues, citrate synthase activity remained unchanged. Taurine preferentially rescued changes in genes concerned with fatty acid metabolism in liver and with oxidative phoshorylation and tri carboxylic acid (TCA) cycle in skeletal muscle. Conclusion: Gestational protein restriction resulted in lower birthweight associated with significant gene expression changes, which was different in liver and muscle of offspring. However, a major part of the birthweight decrease and the expression changes were prevented by maternal taurine supplementation, implying taurine is a key component in metabolic fetal programming. (Pediatr Res 67: 47-53, 2010)
\end{abstract}

$\mathrm{I}_{\mathrm{b}}^{\mathrm{n}}$ mpaired fetal growth resulting in low birth weight has long been associated with increased risk of developing abnormal metabolic functions in adulthood (1). Hence, low birth weight increases the risk of developing obesity and type 2 diabetes later in life in humans (2). A low birth weight in humans is associated with impaired insulin signaling in skeletal muscle in adult life (3-5), hepatic insulin resistance (6), and decreased insulin secretion (7). The exact mechanism whereby impaired fetal growth confers insulin resistance in the offspring is

Received June 18, 2009; accepted September 10, 2009.

Correspondence: Ole Hartvig Mortensen, Ph.D., Department of Biomedical Sciences, University of Copenhagen, Panum 6.5, Blegdamsvej 3, DK-2200, Copenhagen, Denmark; e-mail: ole@ hartvig.org

Supported by grants from the Danish Research Council (Center for Pharmocogenomics), the Danish Council for Strategic Research 2101-05-0030, and the Toyota Foundation. Supported by a grant from the Danish Medical Research Council, grant 271-07-0732 (O.H.M.).

Supplemental digital content is available for this article. Direct URL citations appear in the printed text and are provided in the HTML and PDF versions of this article on the journal's Web site (www.pedresearch.org). unknown, but mitochondrial oxidative stress was recently proposed as a possible mechanism (8).

Several animal models mimicking impaired fetal growth have been developed, all of which display dysregulated glucose metabolism and altered insulin sensitivity in adult life (9). One such model is gestational protein restriction, where dams are fed a low protein (LP) diet during pregnancy (9). Most studies on the effects of a maternal LP diet have focused on beta-cell dysfunction (9), although the influence of maternal LP diet on peripheral insulin sensitivity has also been studied, showing an increase in young animals (10) but a decrease in old animals $(11,12)$.

Taurine is a sulfur-containing amino acid, which does not enter protein synthesis but has a number of other physiologic functions such as conjugation with bile acids, osmotic pressure regulation in brain, and antioxidant properties. Taurine is a chemical chaperone in conjugation with ursodeoxycholic acid relieving endoplasmatic reticulum stress, and it may be required for optimal mitochondrial protein synthesis through taurine modified tRNAs. It has also recently been suggested to be involved in skeletal muscle fatigue, most likely due to mitochondrial effects (13-15). Furthermore, taurine seems to have a positive effect on glucose homeostasis in type 2 diabetic patients $(15,16)$ and has in rodents been shown to prevent or delay development of insulin resistance induced by fructose-overfeeding (17) as well as improving glucose homeostasis (18). However, the mechanism(s) whereby taurine exerts these effects is not known. Several studies have documented that taurine ameliorates some of the harmful effects that a maternal LP diet confers on the pancreas of the offspring by normalizing proliferation (19) and vascularization in pancreatic islets, and decreasing sensitivity of the pancreatic islets toward cytokines (20). Collectively, these studies suggest that taurine has a "reprogramming" or rescuing effect during fetal development, perhaps via epigenetic and/or organogenesisrelated mechanisms. There is, however, no information on possible taurine effects on the development of peripheral organs like skeletal muscle and liver in fetal life.

\footnotetext{
Abbreviations: CS, citrate synthase; LP, low protein; NP, normal protein; PGC-1 $\alpha$, peroxisome proliferator-activated receptor $\gamma$; coactivator-1 $\alpha$, Tau; taurine, TCA, tri carboxylic acid
} 
In this study, we report that a maternal LP diet induces significant and qualitatively different changes in gene expression in liver and skeletal muscle and that taurine partially prevents the change in $30 \%$ of these expression changes in liver and $46 \%$ in skeletal muscle.

\section{METHODS}

Animals. Virgin female (7-8 wk old, $n=3$ per diet group) C57BL/6 mice (Taconic, Ejby, Denmark) were mated with C57BL/6 male mice. After observation of a vaginal plug (gestation day 0 ), the mice were randomized into four different diet groups: Normal protein (20\% casein; NP; Hope Farms 4400.00, Woerden, NL) or LP (8\% casein; LP; Hope Farms 4400.01) with or without $1 \%(\mathrm{wt} / \mathrm{vol})$ taurine in the drinking water (tau, i.e. NP + tau or LP + tau) (synthetic taurine; Sigma Chemical Co.-Aldrich, St. Louis, MO).

The four different diet groups were considered largely isocaloric because the taurine supplementation contributed only marginally to the calorie intake: Mice drink approximately $7 \mathrm{~mL}$ of water per day and eat approximately $7 \mathrm{~g}$ of chow per day (21). For an NP diet, this corresponds to a total chow protein intake per day of $1.4 \mathrm{~g}$ protein ( $20 \%$ casein) or roughly $0.22 \mathrm{~g} \mathrm{~N}$-equivalents

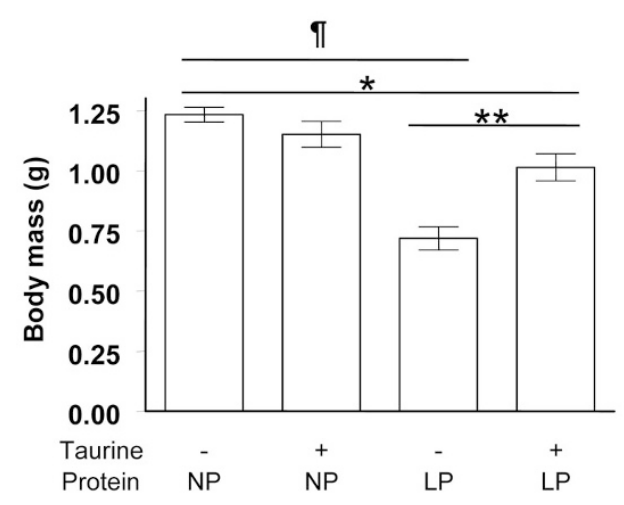

Figure 1. Maternal LP diet confers changes in body mass; partial rescue by taurine. Newborn mice subjected to different diet regimes in utero as described in materials and methods were weighed at birth. NP (20\% casein) or LP ( $8 \%$ casein) during pregnancy. Taurine, $1 \%$ taurine supplementation in the drinking water during pregnancy. If, $p<0.001 \mathrm{NP} v s$. LP; ${ }^{* *}, p<0.01 \mathrm{LP}$ vs. LP + tau; $*, p<0.05 \mathrm{NP} v s . \mathrm{LP}+$ tau. Bars depict means \pm SEM $5 \leq$ $n \leq 7$ per diet group. per day (assuming $16 \%$ nitrogen). Similarly, total chow protein intake per day for the LP diet (8\% casein) is $0.56 \mathrm{~g}$ protein or roughly $0.09 \mathrm{~g} \mathrm{~N}$-equivalents. The taurine enriched water will supply $0.07 \mathrm{~g}$ taurine or $0.0078 \mathrm{~g}$ $\mathrm{N}$-equivalents (taurine content is $11.2 \%$ nitrogen), i.e. less than a $10 \%$ increase of the nitrogen intake. Irrespective of its $\mathrm{N}$-contribution, taurine cannot make up for the decreased intake of essential amino acids caused by the LP diet.

Mice were kept in a 12-h light/dark cycle. At day 19, the mice gave birth and newborn pups were weighed, killed by decapitation and liver and hind leg skeletal muscle quickly and quantitatively removed, weighed, quick frozen in liquid nitrogen and stored at $-80^{\circ} \mathrm{C}$ for further analysis. A total of 25 pups from 12 different dams were analyzed, with $5 \leq n \leq 7$ pups per group, all groups being a mixture of male and female pups. All experimental procedures were approved by The National Committee on Animal Experimentation, Denmark and by the local animal facility at the University of Copenhagen, Denmark.

\section{RESULTS}

Birthweight and enzyme activities in liver and muscle of newborn mice. Mouse dams were subjected to four different isocaloric diet regimes from day 1 of pregnancy until giving birth as described in materials and methods. The LP diet caused a $\sim 40 \%$ decrease $(p<0.001)$ of the birth weight of the pups (Fig. 1 and Table 1). Supplementing the maternal LP diet with taurine reduced the birth weight loss by half $(p<0.01)$ (Fig. 1; Table 1). Both liver and skeletal muscle mass of newborn pups were decreased in proportion to body weight by the maternal LP diet (Table 1).

As a measure of the mitochondrial fraction of tissue mass, citrate synthase (CS) specific enzyme activity and mRNA level (22) was determined in liver and skeletal muscle of the newborn pups. There was no difference between diet groups in either CS mRNA levels (Table S1, http://links.lww.com/PDR/A56) or CS enzyme specific activities (Table 1). Similarly, we detected no difference between diet groups with regard to creatine kinase specific activity in skeletal muscle. Lactate dehydrogenase specific activity increased in skeletal muscle with taurine supplementation $(p<0.05)$, whereas there was no such effect in liver (Table 1).

Table 1. Maternal low protein diet confers changes in body mass, but not in liver and skeletal muscle citrate synthase specific activity in newborn mice

\begin{tabular}{|c|c|c|c|c|c|c|c|}
\hline & \multicolumn{2}{|c|}{$\mathrm{NP}$} & \multicolumn{2}{|c|}{ LP } & \multicolumn{3}{|c|}{ 2-way ANOVA } \\
\hline & Taurine-- & Taurine + & Taurine- & Taurine + & Chow & Taurine & $\mathrm{c} \times \mathrm{t}$ \\
\hline Body mass (BM; g) & $1.23 \pm 0.03$ & $1.15 \pm 0.05$ & $0.72 \pm 0.05^{*}$ & $1.01 \pm 0.06 \dagger+$ & 0.0001 & 0.037 & 0.0008 \\
\hline Liver mass (mg) & $56.9 \pm 2.75$ & $51.8 \pm 3.98$ & $32.2 \pm 2.08 *$ & $44.2 \pm 4.32$ & 0.0002 & $\mathrm{~ns}$ & 0.0243 \\
\hline Muscle mass (mg) & $20.1 \pm 1.95$ & $22.3 \pm 2.49$ & $10.6 \pm 2.18$ & $17.5 \pm 1.77$ & 0.0030 & $(0.0537)$ & ns \\
\hline Liver $(\%$ of $\mathrm{BM})$ & $4.60 \pm 0.15$ & $4.48 \pm 0.19$ & $4.62 \pm 0.56$ & $4.32 \pm 0.20$ & ns & $\mathrm{ns}$ & ns \\
\hline Muscle (\% of BM) & $1.62 \pm 0.13$ & $1.99 \pm 0.28$ & $1.59 \pm 0.47$ & $1.71 \pm 0.10$ & ns & ns & ns \\
\hline CS liver (mU/mg) & $80.2 \pm 5.7$ & $85.1 \pm 2.5$ & $74.7 \pm 4.3$ & $75.6 \pm 3.8$ & $(0.0825)$ & ns & ns \\
\hline CS muscle (mU/mg) & $127.1 \pm 12.2$ & $133.1 \pm 8.5$ & $140.7 \pm 15.3$ & $149.9 \pm 13.4$ & $\mathrm{~ns}$ & ns & ns \\
\hline LDH liver (U/mg) & $5.7 \pm 0.3$ & $5.4 \pm 0.3$ & $4.2 \pm 0.2$ & $5.4 \pm 0.5$ & $(0.0595)$ & ns & $(0.0567)$ \\
\hline LDH muscle (U/mg) & $1.6 \pm 0.1$ & $1.8 \pm 0.2$ & $1.3 \pm 0.1$ & $1.8 \pm 0.1$ & $\mathrm{~ns}$ & 0.0354 & $\mathrm{~ns}$ \\
\hline CK muscle (U/mg) & $11.3 \pm 0.9$ & $12.6 \pm 1.0$ & $9.0 \pm 1.3$ & $11.4 \pm 0.7$ & ns & ns & ns \\
\hline
\end{tabular}

Newborn mice subjected to different diet regimes in utero as described in materials and methods were weighed at birth and killed. Liver and skeletal muscle tissue were extracted, weighed, and citrate synthase (CS; mU/mg protein), lactate dehydrogenase (LDH; U/mg protein), and creatine kinase (CK; U/mg protein) enzyme activity measured as described (Supplemental methods, http://links.lww.com/PDR/A56). BM, Body mass; NP, (20\% casein), or LP (8\% casein) during pregnancy. Taurine, $1 \%$ taurine supplementation in the drinking water during pregnancy. Bonferroni corrected post hoc t tests performed if chow $\times$ taurine $(\mathrm{c} \times \mathrm{t})$ interaction was significant.

All values are shown as means \pm SEM. $5 \leq \mathrm{N} \leq 7$ per diet group.

$* p<0.001 \mathrm{NP}$ vs. LP.

$\dagger p<0.01 \mathrm{LP}$ vs. LP + taurine.

$\ddagger p<0.05 \mathrm{NP}$ vs. LP + taurine. 
Effects of a maternal LP diet on gene expression levels in liver and skeletal muscle of newborn mice. Gene expression profiles of three randomly chosen offspring samples from each diet group of both liver and skeletal muscle were analyzed using Affymetrix gene expression microarrays as described (Supplemental methods, http://links.lww.com/PDR/A56) (Table 2; Fig. $2 A$ and $C$ ).

In liver, the expression of a total of 2012 nonredundant transcripts, all encoding known genes, were significantly

Table 2. General data from the microarray analyses

\begin{tabular}{|c|c|c|}
\hline Description & Liver & Muscle \\
\hline $\begin{array}{l}\text { Total number of probes on the Affymetrix Mouse } \\
4302.0 \text { gene expression array }\end{array}$ & 45101 & 45101 \\
\hline Number of probes present on at least one array & 28653 & 30966 \\
\hline $\begin{array}{l}\text { Above without control probes or probes without } \\
\text { a valid EntrezGene identifier }\end{array}$ & 27300 & 29443 \\
\hline $\begin{array}{l}\text { Probes significantly changed in SAM } \\
\text { preprocessing }(\text { FDR }<10 \%)\end{array}$ & 6047 & 1559 \\
\hline $\begin{array}{l}\text { Probes significantly changed }(p<0.05) \text { in } \\
\text { two-way ANOVA }\end{array}$ & 3678 & 1284 \\
\hline $\begin{array}{l}\text { Probes significantly different }(p<0.05) \text { between } \\
\text { NP and LP }\end{array}$ & 2827 & 1272 \\
\hline $\begin{array}{l}\text { Unique genes significantly different }(p<0.05) \\
\text { between NP and LP }\end{array}$ & 2363 & 1110 \\
\hline $\begin{array}{l}\text { Known genes significantly different }(p<0.05) \\
\text { between NP and LP }\end{array}$ & 2012 & 967 \\
\hline $\begin{array}{l}\text { Known genes different between NP and LP and } \\
\text { fully rescued by taurine }\end{array}$ & 510 & 423 \\
\hline $\begin{array}{l}\text { Known genes different between NP and LP and } \\
\text { partially rescued by taurine }\end{array}$ & 90 & 21 \\
\hline Total number of known genes rescued by taurine & 600 & 444 \\
\hline $\begin{array}{l}\text { Percentage known genes different between NP } \\
\text { and LP rescued by taurine (\%) }\end{array}$ & 30 & 46 \\
\hline
\end{tabular}

A list of probe or gene numbers detailing the microarray gene expression analyses of liver and skeletal muscle of newborn mice, as described (Supplemental methods, http://links.lww.com/PDR/A56). NP (20\% casein) or LP (8\% casein) during pregnancy. changed by the maternal LP diet (Table S5A, http:// links.lww.com/PDR/A56), while a somewhat smaller number of 967 nonredundant transcripts, all encoding known genes, were changed in skeletal muscle (Table S5B, http:// links.lww.com/PDR/A56) (pairwise false discovery rate $<10 \%$ ). There was an overlap of 210 known genes, for which changes in expression levels were seen in both liver and skeletal muscle (Table S5C, http://links.lww.com/PDR/ A56). Of the 2012 known genes affected in the liver, 667 transcripts were up- and 1345 down-regulated. Similarly, in skeletal muscle, of the 967 known genes affected, 312 were up- and 655 transcripts were down-regulated compared with a maternal NP diet.

A number of significantly changed transcripts and one not significantly changed (CS) were randomly selected for RTPCR validation of the microarray data. Positive validation was obtained for seven out of eight and six out of nine transcripts encoding known genes in liver and skeletal muscle, respectively (Table S1, http://links.lww.com/PDR/A56).

Taurine partially rescues the maternal LP diet offspring phenotype. Taurine supplementation to the mother had no effect on the gene expression patterns in the offspring of the NP diet groups (Fig. 2; statistical analysis comparing NP with $\mathrm{NP}+$ tau, data not shown). In contrast, taurine supplementation prevented a major part of the gene expression changes seen with the maternal LP diet (Fig. 2; Table 2). Qualitatively, this is most clearly demonstrated when comparing all genes whose expression was changed by the LP $\operatorname{diet}$ (Fig. $2 A$ and $2 C$ ) with those that were rescued (Fig. $2 B$ and $2 D$ ) and noticing that in the latter, the LP + tau samples cluster together with NP and NP + tau in both liver and skeletal muscle. In all, taurine had a rescuing effect on $30 \%$ (600 out of 2012) of the changed transcripts of known genes in liver and on 46\% (444 out of 967) in skeletal muscle (Table 2),

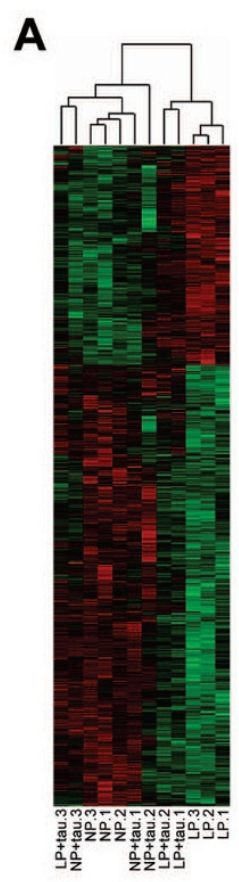

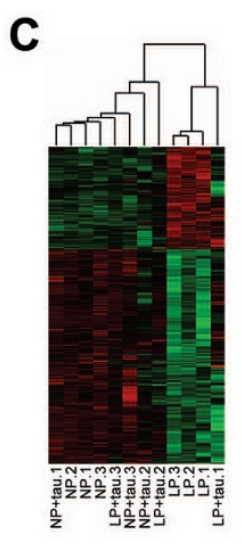

Figure 2. Liver and skeletal muscle gene expression profiling of newborn mice subjected to a maternal LP diet with or without taurine supplementation. Hierarchical clustering of samples and expression patterns of genes significantly different between newborn mice subjected to either a maternal LP diet or a maternal NP diet. (A) Liver (2012 genes), (B) liver, genes rescued by taurine (600 genes), (C) skeletal muscle ( 967 genes), $(D)$ skeletal muscle, genes rescued by taurine (444 genes). NP (20\% casein) or LP ( $8 \%$ casein) during pregnancy, tau, $1 \%$ taurine supplementation in the drinking water during pregnancy. Numbers indicate biologic replicates. 
rendering the taurine effect more pronounced on muscle than on liver $\left(p<10^{-16}\right.$, Fishers exact test).

Among the changed genes, we found that mitochondrial genes (Tables S2 \& S3, http://links.lww.com/PDR/A56) and among those in particular genes involved in oxidative phosphorylation (Table S4, http://links.lww.com/PDR/A56) were the most over-represented gene sets in both liver and skeletal muscle (Tables 3 and 4). Genes involved in tri carboxylic acid (TCA) cycle, pyruvate metabolism, and glycolysis were over represented only in skeletal muscle (Table 4). Over representation of genes involved in amino acid metabolism was observed both in liver and skeletal muscle (Tables 3 and 4). However, the key regulator of mitochondrial biogenesis, peroxisome proliferator-activated receptor $\gamma$ coactivator- $1 \alpha$

Table 3. Analysis of gene set over-representation in liver

\begin{tabular}{|c|c|c|c|c|c|c|c|c|}
\hline \multirow[b]{2}{*}{ Category } & \multirow[b]{2}{*}{ Count } & \multirow[b]{2}{*}{ Ease score } & \multirow[b]{2}{*}{$\%$ Rescued } & \multirow[b]{2}{*}{ Taurine score } & \multicolumn{4}{|c|}{ Average fold change } \\
\hline & & & & & NP & $\mathrm{NP}+\mathrm{tau}$ & LP & $\mathrm{LP}+\mathrm{tau}$ \\
\hline All genes & 2012 & na & 30 & na & 1 & 0.96 & 0.95 & 0.96 \\
\hline KEGG pathway analysis & 620 & na & 31 & na & 1 & 0.97 & 1.02 & 1.01 \\
\hline mmu00190:Oxidative phosphorylation & 42 & $1.56 \mathrm{E}-06$ & 43 & 0.125 & 1 & 1.06 & 1.44 & 1.21 \\
\hline mmu00280:Valine, leucine, and isoleucine degradation & 17 & $3.13 \mathrm{E}-03$ & 24 & 0.604 & 1 & 1.04 & 1.47 & 1.27 \\
\hline mmu00310:Lysine degradation & 17 & $4.12 \mathrm{E}-03$ & 41 & 0.428 & 1 & 1.02 & 1.40 & 1.24 \\
\hline mmu00650:Butanoate metabolism & 15 & $2.04 \mathrm{E}-02$ & 27 & 1 & 1 & 0.99 & 1.16 & 1.19 \\
\hline mmu00903:Limonene and pinene degradation & 10 & $2.06 \mathrm{E}-02$ & 20 & 0.732 & 1 & 0.98 & 1.15 & 1.14 \\
\hline Panther biological pathways & 1965 & na & 30 & na & 1 & 0.96 & 0.95 & 0.96 \\
\hline BP00020:Fatty acid metabolism & 122 & $7.90 \mathrm{E}-05$ & 40 & 0.027 & 1 & 0.95 & 0.86 & 0.94 \\
\hline BP00069:Protein disulfide-isomerase reaction & 90 & $1.16 \mathrm{E}-04$ & 29 & 0.907 & 1 & 0.99 & 1.04 & 1.01 \\
\hline BP00077:Oxidative phosphorylation & 175 & $1.63 \mathrm{E}-03$ & 28 & 0.606 & 1 & 0.94 & 0.97 & 0.97 \\
\hline BP00148:Immunity and defense & 171 & $2.34 \mathrm{E}-03$ & 30 & 1 & 1 & 0.99 & 0.86 & 0.95 \\
\hline BP00001:Carbohydrate metabolism & 86 & $4.54 \mathrm{E}-03$ & 32 & 0.722 & 1 & 0.97 & 1.07 & 1.05 \\
\hline GO cellular component & 1627 & na & 30 & na & 1 & 0.96 & 0.95 & 0.96 \\
\hline GO:0005739—mitochondrion & 209 & $4.71 \mathrm{E}-11$ & 37 & 0.057 & 1 & 1.03 & 1.29 & 1.13 \\
\hline GO:0005737— cytoplasm & 866 & $4.53 \mathrm{E}-08$ & nd & nd & nd & nd & nd & nd \\
\hline GO:0044424 —intracellular part & 1231 & $2.51 \mathrm{E}-07$ & nd & nd & nd & nd & nd & nd \\
\hline GO:0005743-mitochondrial inner membrane & 68 & $1.21 \mathrm{E}-06$ & nd & nd & nd & nd & nd & nd \\
\hline GO:0019866 — organelle inner membrane & 69 & $3.63 \mathrm{E}-06$ & nd & nd & nd & nd & nd & nd \\
\hline
\end{tabular}

Genes found to have their expression level significantly changed in liver in newborn mice subjected to a maternal low protein diet compared to a normal diet were examined for over representation of specific gene sets as described (Supplemental methods, http://links.lww.com/PDR/A56). The top 5 most significant over-represented gene sets are shown.

Count, total number of genes in analysis; Ease score, a modified Fisher exact test describing the probability of gene set enrichment; \% Rescued, amount of rescued or partially rescued genes (see table 1) in percent of count; Taurine score, Fisher exact test examining if taurine preferentially rescued the gene set compared to the rescue effect seen in all genes examined in the parent geneset; Average fold change, means of fold change for the four diet groups per gene set in regard to NP. NP (20\% casein) or LP ( $8 \%$ casein) during pregnancy, tau, $1 \%$ taurine supplementation in the drinking water during pregnancy.

na, not applicable; nd, not determined.

Table 4. Analysis of gene set over-representation in skeletal muscle

\begin{tabular}{|c|c|c|c|c|c|c|c|c|}
\hline \multirow[b]{2}{*}{ Category } & \multirow[b]{2}{*}{ Count } & \multirow[b]{2}{*}{ Ease score } & \multirow[b]{2}{*}{$\%$ Rescued } & \multirow[b]{2}{*}{ Taurine score } & \multicolumn{4}{|c|}{ Average fold change } \\
\hline & & & & & $\mathrm{NP}$ & $\mathrm{NP}+\mathrm{tau}$ & LP & $\mathrm{LP}+\mathrm{tau}$ \\
\hline All genes & 967 & na & 46 & na & 1 & 0.98 & 0.95 & 0.94 \\
\hline KEGG pathway analysis & 263 & na & 46 & na & 1 & 0.99 & 0.90 & 0.93 \\
\hline mmu00190:Oxidative phosphorylation & 24 & $5.60 \mathrm{E}-06$ & 75 & 0.010 & 1 & 0.92 & 0.72 & 1.04 \\
\hline mmu00020:Citrate cycle (TCA cycle) & 8 & $2.45 \mathrm{E}-03$ & 88 & 0.029 & 1 & 0.96 & 0.58 & 0.93 \\
\hline mmu00280:Valine, leucine, and isoleucine degradation & 10 & $4.53 \mathrm{E}-03$ & 40 & 0.757 & 1 & 1.02 & 0.59 & 0.81 \\
\hline mmu00620:Pyruvate metabolism & 9 & $9.62 \mathrm{E}-03$ & 67 & 0.314 & 1 & 0.99 & 0.49 & 0.86 \\
\hline mmu00010:Glycolysis/gluconeogenesis & 10 & $1.12 \mathrm{E}-02$ & 60 & 0.523 & 1 & 0.96 & 0.61 & 0.98 \\
\hline Panther biological pathways & 928 & na & 46 & na & 1 & 0.98 & 0.94 & 0.94 \\
\hline BP00076:Electron transport & 65 & $3.99 \mathrm{E}-04$ & 45 & 1 & 1 & 0.96 & 0.84 & 0.98 \\
\hline BP00173:Muscle contraction & 13 & $5.12 \mathrm{E}-03$ & 64 & 0.189 & 1 & 0.84 & 0.38 & 0.84 \\
\hline BP00120:Cell adhesion-mediated signaling & 33 & $5.85 \mathrm{E}-03$ & 52 & 0.596 & 1 & 0.99 & 1.06 & 0.99 \\
\hline BP00287:Cell motility & 48 & $9.44 \mathrm{E}-03$ & 44 & 0.769 & 1 & 1.00 & 1.16 & 0.97 \\
\hline BP00142:Ion transport & 133 & $1.21 \mathrm{E}-02$ & 53 & 0.164 & 1 & 0.97 & 0.94 & 0.93 \\
\hline GO cellular component & 777 & na & 47 & na & 1 & 0.98 & 0.94 & 0.94 \\
\hline GO:0005739—mitochondrion & 121 & $2.46 \mathrm{E}-13$ & 56 & 0.065 & 1 & 0.97 & 0.62 & 0.91 \\
\hline GO:0044444_cytoplasmic part & 288 & $8.48 \mathrm{E}-10$ & nd & nd & nd & nd & nd & nd \\
\hline GO:0005737_ cytoplasm & 441 & $1.57 \mathrm{E}-09$ & nd & nd & nd & nd & nd & nd \\
\hline GO:0044429 — mitochondrial part & 56 & $4.70 \mathrm{E}-09$ & nd & nd & nd & nd & nd & nd \\
\hline GO:0005743-mitochondrial inner membrane & 42 & $1.12 \mathrm{E}-07$ & nd & nd & nd & nd & nd & nd \\
\hline
\end{tabular}

Genes found to have their expression level significantly changed in skeletal muscle in newborn mice subjected to a maternal low protein diet compared to a normal diet were examined for over-representation of specific gene sets as described (Supplemental methods, http://links.lww.com/PDR/A56). The top 5 most significant over-represented gene sets are shown. Count, Ease score, \% rescued, Taurine score, and average fold change are described in Table 3. 

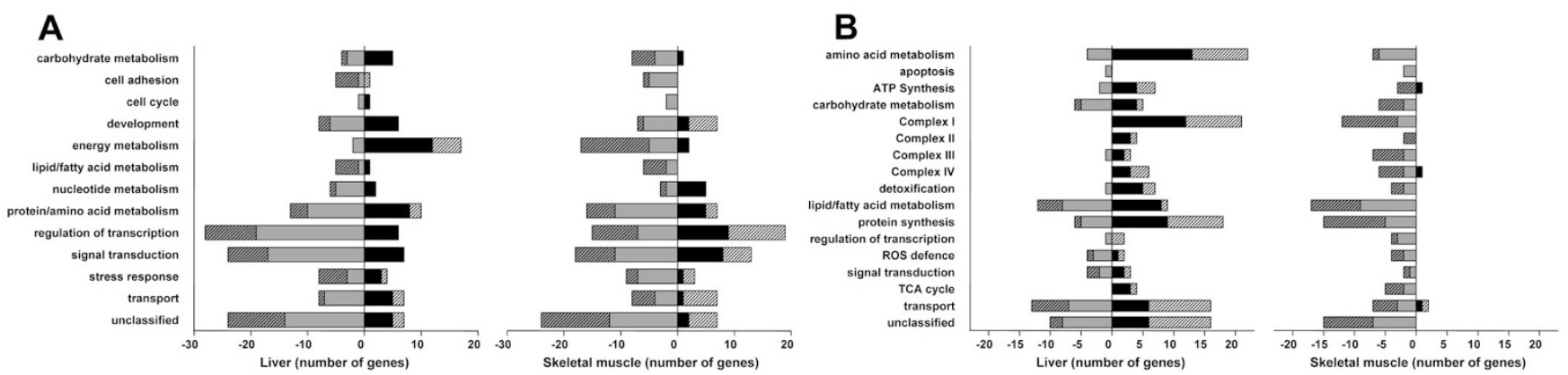

Figure 3. Classification of changed genes by biologic function. A, Genes significantly changed in newborn mice in response to an in utero LP diet in liver and skeletal muscle. For comparison, only genes that were changed in both liver and skeletal muscle are shown. $B$, Mitochondrial genes changed in newborn mice in response to an in utero LP diet in liver and skeletal muscle. Gray/black bars indicate down/up-regulated genes in newborn mice subjected to a LP diet in utero compared with a NP diet. Hatched bars indicate the number of genes rescued by taurine supplementation.

(PGC-1 $\alpha$ ), was down-regulated by the LP diet in both tissues (Table S1, http://links.lww.com/PDR/A56).

When genes were grouped according to function (Fig. 3A), a large difference was seen between up- and down-regulated genes in energy metabolism in both liver and skeletal muscle, albeit in a different direction in the two tissues. Similarly, when the largest significant gene set, mitochondrial genes (Fig. 3B), was grouped according to function, a clear difference between liver and skeletal muscle could be seen. No overt difference in the taurine rescue effect was seen between tissues when genes were grouped according to function.

The rescuing effect of taurine was significantly higher on genes involved in fatty acid metabolism in liver compared with other gene sets ( $p=0.027$, Fishers exact test) (Table 3), whereas in skeletal muscle this rescuing effect was present only for genes involved in oxidative phosphorylation and the TCA cycle ( $p=0.010$ and $p=0.029$, respectively, Fishers exact test) (Table 4).

\section{DISCUSSION}

The novel findings of this study were 1) that a maternal LP diet induced substantial changes in gene expression patterns in newborn offspring in both liver and skeletal muscle, 2) that the changes in mitochondrial genes in general and genes of oxidative phosphorylation in particular were prominent in both liver and skeletal muscle, with predominantly up-regulation in liver and down-regulation in skeletal muscle, and finally 3) that maternal taurine supplementation in the drinking water during pregnancy to a surprisingly large extent prevented these changes in gene expression patterns in both liver and skeletal muscle (preventing 30\% in liver and $46 \%$ in muscle). Importantly, taurine also partially prevented the decrease in birthweight caused by a maternal LP diet.

Birth weight. We found a $40 \%$ decrease in birthweight of LP offspring compared with NP offspring. This is a somewhat larger decrease in birthweight than previously reported in rodents, i.e. $18-35 \%$ in rats $(11,23)$ and $28 \%$ in C57BL/6 mice (24), whereas others have observed only a $7 \%$ weight loss in the same mouse strain (25), most likely due to differences in diet composition. We observed no difference in the ratio of organ weight:total body weight, which seems to disagree with a previous study in rats (23).
Furthermore, it came as a surprise that taurine supplementation almost prevented the low birthweight; in particular because this effect was not observed in rats in a similar study (19). However, these disagreements likely reflect species differences.

Changes in global gene expression patterns in liver and skeletal muscle. Despite the fact that the NP and LP diets are isocaloric, genes involved in energy metabolism, oxidative phosphorylation, and other mitochondrial genes were the ones most over represented on the list of changed gene sets (Tables 3 and 4). However, as CS activity can be considered a measure of mitochondrial mass (22), the results suggests a dysregulation of gene expression related to mitochondrial function rather than a change in mitochondrial mass. This may be in contrast to studies by Park et al. (26), who found a significant decrease in mtDNA:gDNA ratio in both liver and skeletal muscle in 5-wk-old offspring of maternal LP rats. Although genes of oxidative phosphorylation are over represented in the list of changed genes in both tissues, a striking difference between liver and skeletal muscle was observed (Fig. 3). In liver, a large fraction of genes involved in amino acid metabolism, protein synthesis, TCA cycle, and energy metabolism genes involved in both Complex I-IV and ATP synthesis showed increased expression, whereas in skeletal muscle the opposite effect was observed. One may speculate that these findings can be explained by the difference in the taurine requirement of the two tissues, as the concentration of taurine in skeletal muscle is $\sim 6$-fold higher than in the liver in mice (27), when taking into consideration the decrease in available taurine in LP (28). Furthermore, taurine is a constituent of mitochondrial tRNA (29), and may thus be required for normal mitochondrial function.

In another model of intrauterine growth retardation in rats, uterine artery ligation, hepatic glucose production, the activity of phosphoenolpyruvate carboxykinase, and PGC- $1 \alpha$ was found to be increased in liver (30), and the capacity of oxidative phosphorylation diminished (31). A similar observation was made in skeletal muscle (32). Gestational protein restriction does not suffer from the side effect of a decrease in available $\mathrm{O}_{2}$ as seen in uterine artery ligation and differences in observations may be credited to this. 
Down regulation of oxidative phosphorylation in skeletal muscle has in several cases been linked to development of type 2 diabetes and insulin resistance (33-35). Although the exact mechanism is unknown, a decrease in the number of skeletal muscle mitochondria and/or in the activity of oxidative phosphorylation as well as mitochondrial dysfunction at birth may, if it is permanent, be associated with a decreased capacity for $\beta$-oxidation, which may lead to increased intracellular lipid content and subsequent disruption of insulin signaling (36). However, this hypothesis has recently been questioned (37).

Interestingly, in humans birthweight is positively associated with the expression of PGC- $1 \alpha$ in skeletal muscle in adults (6), but despite PGC- $1 \alpha$ controlling mitochondrial biogenesis (38), no concomitant difference in mitochondrial gene expression and oxidative phosphorylation was observed in adults with a low birthweight (6). However, the decrease in mitochondrial gene expression seen in this study, and not in adult humans, may reflect the difference between newborns and adults or species difference.

Partial phenotype rescue by taurine supplementation. Taurine has previously been shown to rescue the detrimental effects of a maternal LP diet regarding pancreatic function in the offspring $(19,20,39,40)$. However, such effects have not been examined in liver and skeletal muscle.

We find a large rescuing effect on gene expression profiles in both liver and muscle by taurine supplementation, with significantly more mitochondrial genes rescued in skeletal muscle than in liver, suggesting a preferential mitochondrial rescue effect by taurine in skeletal muscle compared with liver. Furthermore, we were surprised to find that taurine exhibited an even more specific rescue effect, as genes of fatty acid metabolism in the liver and genes involved in oxidative phosphorylation and TCA cycle in skeletal muscle were preferentially rescued compared with other genes (Tables 3-4; Table S4, http://links.lww.com/PDR/A56). A similar study examining the effect of maternal LP diet and taurine on islet gene expression also found decreased expression of respiration and TCA cycle genes, changes which were rescued fully by taurine supplementation (40). Combined with our results, this strongly suggests that the effect exerted by taurine is mediated by a mitochondrial mechanism.

Plasma taurine concentration has been suggested to be a marker of fetal well being (41), and it has been suggested that sufficient taurine plasma concentrations may be a prerequisite for normal fetal development (41). This is corroborated by the observation that lack of the taurine transporter (TAUT) confers a large decrease in exercise capacity (13), which may also be related to the observation that TAUT expression increases during myogenesis and that taurine is able to protect against dexamethasone induced atrophy (42). Thus, a picture of taurine as a necessary factor in myogenesis, and perhaps mitochondrial biogenesis, emerges.

In liver, a deficiency of taurine, as seen in the TAUT knockout mouse, causes an increase in hepatic apoptosis and inflammation, as well as a decrease in mitochondrial respiratory control ratio (43). Also, taurine has been shown to have an anti-apoptotic effect on the liver and to normalize tamox- ifen induced mitochondrial dysfunction in rats (44). There are several reports on the effect of a maternal LP diet on offspring DNA methylation patterns $(45,46)$, but there is no evidence of taurine involvement in this process. Interestingly, taurine has been shown to decrease N-methylation in rat heart (47).

Methodological considerations. The C57BL/6 mice are hypertaurinuric (15), and it is important to consider whether the taurine effect could be caused by the extra nitrogen or sulfur supplied as taurine. The nitrogen supply by taurine is a minor fraction of the total nitrogen intake (see Materials and Methods), and it is unlikely that the taurine effects seen in this study are due to an increase in sulfur amino acid availability because there appears to be very little, if any, metabolic conversion of taurine into methionine or cysteine (48). Most other similar studies have used a higher concentration of taurine in the drinking water $(2.0 \%$ or $2.5 \%)(19,20,39,40)$ than the $1 \%$ concentration used in this study.

In conclusion, a LP diet to mice during pregnancy caused major changes in both body mass and gene expression profiles of liver and skeletal muscle of the newborn mice. The expression changes were predominantly related to mitochondrial genes but were markedly different in liver and skeletal muscle. Maternal taurine supplementation in the drinking water partially prevented both the change in body mass and changes in gene expression. In particular, skeletal muscle genes involved in oxidative phosphorylation were almost completely normalized by the taurine supplementation. The mechanism of these taurine effects remains unknown.

\section{REFERENCES}

1. Hales CN, Barker DJ 2001 The thrifty phenotype hypothesis. Br Med Bull 60:5-20

2. Vaag A, Jensen CB, Poulsen P, Brons C, Pilgaard K, Grunnet L, Vielwerth S, Alibegovic A 2006 Metabolic aspects of insulin resistance in individuals born small for gestational age. Horm Res 65(suppl 3):137-143

3. Jensen CB, Martin-Gronert MS, Storgaard H, Madsbad S, Vaag A, Ozanne SE 2008 Altered PI3-kinase/Akt signalling in skeletal muscle of young men with low birth weight. PLoS One 3:e3738

4. Ozanne SE, Jensen CB, Tingey KJ, Storgaard H, Madsbad S, Vaag AA 2005 Low birthweight is associated with specific changes in muscle insulin-signalling protein expression. Diabetologia 48:547-552

5. Ozanne SE, Jensen CB, Tingey KJ, Martin-Gronert MS, Grunnet L, Brons C, Storgaard H, Vaag AA 2006 Decreased protein levels of key insulin signalling molecules in adipose tissue from young men with a low birthweight: potential link to increased risk of diabetes? Diabetologia 49:2993-2999

6. Brons C, Jensen CB, Storgaard H, Alibegovic A, Jacobsen S, Nilsson E, Astrup A, Quistorff B, Vaag A 2008 Mitochondrial function in skeletal muscle is normal and unrelated to insulin action in young men born with low birth weight. J Clin Endocrinol Metab 93:3885-3892

7. Poulsen P, Levin K, Beck-Nielsen H, Vaag A 2002 Age-dependent impact of zygosity and birth weight on insulin secretion and insulin action in twins. Diabetologia 45:1649-1657

8. Luo ZC, Fraser WD, Julien P, Deal CL, Audibert F, Smith GN, Xiong X, Walker M 2006 Tracing the origins of "fetal origins" of adult diseases: programming by oxidative stress? Med Hypotheses 66:38-44

9. Martin-Gronert MS, Ozanne SE 2007 Experimental IUGR and later diabetes. J Intern Med 261:437-452

10. Shepherd PR, Crowther NJ, Desai M, Hales CN, Ozanne SE 1997 Altered adipocyte properties in the offspring of protein malnourished rats. Br J Nutr 78:121-129

11. Fernandez-Twinn DS, Wayman A, Ekizoglou S, Martin MS, Hales CN, Ozanne SE 2005 Maternal protein restriction leads to hyperinsulinemia and reduced insulinsignaling protein expression in 21-mo-old female rat offspring. Am J Physiol Regul Integr Comp Physiol 288:R368-R373

12. Petry CJ, Dorling MW, Pawlak DB, Ozanne SE, Hales CN 2001 Diabetes in old male offspring of rat dams fed a reduced protein diet. Int J Exp Diabetes Res 2:139-143

13. Warskulat U, Flogel U, Jacoby C, Hartwig HG, Thewissen M, Merx MW, Molojavyi A, Heller-Stilb B, Schrader J, Haussinger D 2004 Taurine transporter knockout depletes muscle taurine levels and results in severe skeletal muscle impairment but leaves cardiac function uncompromised. FASEB J 18:577-579

14. Bouckenooghe T, Remacle C, Reusens B 2006 Is taurine a functional nutrient? Curr Opin Clin Nutr Metab Care 9:728-733 
15. Hansen SH 2001 The role of taurine in diabetes and the development of diabetic complications. Diabetes Metab Res Rev 17:330-346

16. Xiao C, Giacca A, Lewis GF 2008 Oral taurine but not N-acetylcysteine ameliorates NEFA-induced impairment in insulin sensitivity and beta cell function in obese and overweight, non-diabetic men. Diabetologia 51:139-146

17. Nandhini AT, Thirunavukkarasu V, Anuradha CV 2005 Taurine modifies insulin signaling enzymes in the fructose-fed insulin resistant rats. Diabetes Metab 31:337344

18. Loizzo A, Carta S, Bennardini F, Coinu R, Loizzo S, Guarino I, Seghieri G, Ghirlanda G, Franconi F 2007 Neonatal taurine administration modifies metabolic programming in male mice. Early Hum Dev 83:693-696

19. Boujendar S, Reusens B, Merezak S, Ahn MT, Arany E, Hill D, Remacle C 2002 Taurine supplementation to a low protein diet during foetal and early postnatal life restores a normal proliferation and apoptosis of rat pancreatic islets. Diabetologia 45:856-866

20. Merezak S, Reusens B, Renard A, Goosse K, Kalbe L, Ahn MT, Tamarit-Rodriguez J, Remacle C 2004 Effect of maternal low-protein diet and taurine on the vulnerability of adult Wistar rat islets to cytokines. Diabetologia 47:669-675

21. Svendsen P, Hau J 1994 Handbook of Laboratory Animal Science. CRC Press, Boca Raton, FL

22. Raffaella C, Francesca B, Italia F, Marina P, Giovanna L, Susanna I 2008 Alterations in hepatic mitochondrial compartment in a model of obesity and insulin resistance. Obesity (Silver Spring) 16:958-964

23. Desai M, Crowther NJ, Lucas A, Hales CN 1996 Organ-selective growth in the offspring of protein-restricted mothers. Br J Nutr 76:591-603

24. Ozanne SE, Lewis R, Jennings BJ, Hales CN 2004 Early programming of weight gain in mice prevents the induction of obesity by a highly palatable diet. Clin Sci (Lond) 106:141-145

25. Morten K, Field P, Ashley N, Williams KA, Harris D, Hartley M, Clark A, Poulton J 2005 Fetal and neonatal exposure to AZT and low-protein diet affects glucose homeostasis: a model with implications for AIDS prevention. Am J Physiol Endocrinol Metab 289:E1115-E1118

26. Park HK, Jin CJ, Cho YM, Park DJ, Shin CS, Park KS, Kim SY, Cho BY, Lee HK 2004 Changes of mitochondrial DNA content in the male offspring of proteinmalnourished rats. Ann N Y Acad Sci 1011:205-216

27. Massie HR, Williams TR, DeWolfe LK 1989 Changes in taurine in aging fruit flies and mice. Exp Gerontol 24:57-65

28. Reusens B, Dahri S, Snoeck A, Bennis-Taleb N, Remacle C, Hoet JJ 1995 Long term consequences of diabetes and its complications may have a fetal origin: experimental and epidemiological evidences. In: Cowett RM (ed) Diabetes. Raven Press, New York, pp 187-198

29. Suzuki T, Suzuki T, Wada T, Saigo K, Watanabe K 2001 Novel taurine-containing uridine derivatives and mitochondrial human diseases. Nucleic Acids Res Suppl $1: 257-258$

30. Lane RH, Maclennan NK, Hsu JL, Janke SM, Pham TD 2002 Increased hepatic peroxisome proliferator-activated receptor-gamma coactivator-1 gene expression in a rat model of intrauterine growth retardation and subsequent insulin resistance. Endocrinology 143:2486-2490

31. Peterside IE, Selak MA, Simmons RA 2003 Impaired oxidative phosphorylation in hepatic mitochondria in growth-retarded rats. Am J Physiol Endocrinol Metab 285:E1258-E1266

32. Selak MA, Storey BT, Peterside I, Simmons RA 2003 Impaired oxidative phosphorylation in skeletal muscle of intrauterine growth-retarded rats. Am J Physiol Endocrinol Metab 285:E130-E137
33. Mootha VK, Lindgren CM, Eriksson KF, Subramanian A, Sihag S, Lehar J, Puigserver P, Carlsson E, Ridderstrale M, Laurila E, Houstis N, Daly MJ, Patterson N, Mesirov JP, Golub TR, Tamayo P, Spiegelman B, Lander ES, Hirschhorn JN, Altshuler D, Groop LC 2003 PGC-1alpha-responsive genes involved in oxidative phosphorylation are coordinately downregulated in human diabetes. Nat Genet 34:267-273

34. Patti ME, Butte AJ, Crunkhorn S, Cusi K, Berria R, Kashyap S, Miyazaki Y, Kohane I, Costello M, Saccone R, Landaker EJ, Goldfine AB, Mun E, DeFronzo R, Finlayson J, Kahn CR, Mandarino LJ 2003 Coordinated reduction of genes of oxidative metabolism in humans with insulin resistance and diabetes: potential role of PGC1 and NRF1. Proc Natl Acad Sci U S A 100:8466-8471

35. Petersen KF, Befroy D, Dufour S, Dziura J, Ariyan C, Rothman DL, DiPietro L, Cline GW, Shulman GI 2003 Mitochondrial dysfunction in the elderly: possible role in insulin resistance. Science 300:1140-1142

36. Roden M 2005 Muscle triglycerides and mitochondrial function: possible mechanisms for the development of type 2 diabetes. Int J Obes (Lond) 2:S111-S115

37. Holloszy JO 2009 Skeletal muscle "mitochondrial deficiency" does not mediate insulin resistance. Am J Clin Nutr 89:463S-466S

38. Ling C, Poulsen P, Carlsson E, Ridderstrale M, Almgren P, Wojtaszewski J, Beck-Nielsen H, Groop L, Vaag A 2004 Multiple environmental and genetic factors influence skeletal muscle PGC-1alpha and PGC-1beta gene expression in twins. J Clin Invest 114:1518-1526

39. Boujendar S, Arany E, Hill D, Remacle C, Reusens B 2003 Taurine supplementation of a low protein diet fed to rat dams normalizes the vascularization of the fetal endocrine pancreas. J Nutr 133:2820-2825

40. Reusens B, Sparre T, Kalbe L, Bouckenooghe T, Theys N, Kruhoffer M, Orntoft TF, Nerup J, Remacle C 2008 The intrauterine metabolic environment modulates the gene expression pattern in fetal rat islets: prevention by maternal taurine supplementation. Diabetologia 51:836-845

41. de Boo HA, Harding JE 2007 Taurine as a marker for foetal wellbeing? Neonatology 91:145-154

42. Uozumi Y, Ito T, Hoshino Y, Mohri T, Maeda M, Takahashi K, Fujio Y, Azuma J 2006 Myogenic differentiation induces taurine transporter in association with taurine-mediated cytoprotection in skeletal muscles. Biochem J 394:699-706

43. Warskulat U, Borsch E, Reinehr R, Heller-Stilb B, Monnighoff I, Buchczyk D, Donner M, Flogel U, Kappert G, Soboll S, Beer S, Pfeffer K, Marschall HU, Gabrielsen M, Amiry-Moghaddam M, Ottersen OP, Dienes HP, Haussinger D 2006 Chronic liver disease is triggered by taurine transporter knockout in the mouse. FASEB J 20:574-576

44. Parvez S, Tabassum H, Banerjee BD, Raisuddin S 2008 Taurine prevents tamoxifeninduced mitochondrial oxidative damage in mice. Basic Clin Pharmacol Toxicol 102:382-387

45. Rees WD, Hay SM, Brown DS, Antipatis C, Palmer RM 2000 Maternal protein deficiency causes hypermethylation of DNA in the livers of rat fetuses. J Nutr 130:1821-1826

46. Kwong WY, Miller DJ, Ursell E, Wild AE, Wilkins AP, Osmond C, Anthony FW, Fleming TP 2006 Imprinted gene expression in the rat embryo-fetal axis is altered in response to periconceptional maternal low protein diet. Reproduction 132:265-277

47. Hamaguchi T, Azuma J, Schaffer S 1991 Interaction of taurine with methionine: inhibition of myocardial phospholipid methyltransferase. J Cardiovasc Pharmacol $18: 224-230$

48. Jacobsen JG, Smith LH 1968 Biochemistry and physiology of taurine and taurine derivatives. Physiol Rev 48:424-511 